\title{
GMR
}

\section{Genetic analysis of molecular markers for propamocarb residue in Cucumis sativus using quantitative trait locus mapping}

\author{
M. Xin ${ }^{1}$, L. Wang', B.H. Ma ${ }^{1,2}$, Z.W. Qin ${ }^{1}$ and X.Y. Zhou ${ }^{1}$ \\ ${ }^{1}$ Hei long jiang Provincial Key University Laboratory of Cold Area Vegetable \\ Biology, Northeast Agricultural University, Harbin, Heilongjiang province, \\ China \\ ${ }^{2}$ School of Resource and Environment of Northeast Agricultural University, \\ Harbin, Heilongjiang province, China \\ Corresponding author: Z.W. Qin \\ E-mail: qzw303@126.com
}

Genet. Mol. Res. 15 (4): gmr15048776

Received May 11, 2016

Accepted September 15, 2016

Published November 3, 2016

DOI http://dx.doi.org/10.4238/gmr15048776

Copyright (C) 2016 The Authors. This is an open-access article distributed under the terms of the Creative Commons Attribution ShareAlike (CC BY-SA) 4.0 License.

\begin{abstract}
The use of pesticides to protect plants against harmful organisms, such as pathogenic microorganisms, is one of the most effective ways to improve agricultural production. However, the continuous use of pesticides might present a risk to human health, animals, and the environment. In this study, two cucumber (Cucumis sativus) varieties containing different levels of pesticide residues, D9320 and D0351, were selected to establish an $\mathrm{F}_{2}$ population. A genetic model and genetic linkage map were constructed. The results showed that the heredity of pesticide residues was dominated by an additive effect and was significantly influenced by non-additive factors in cucumber. $Q C p 1$ was detected as a quantitative trait locus (QTL) that might be involved in regulating the levels of pesticide residue in
\end{abstract}

Genetics and Molecular Research 15 (4): gmr15048776 
cucumber. Moreover, the cucumber genetic map was compared with the LG6 map, and the results indicated that this QTL was closely related to the level of pesticide residue in cucumber.

Key words: Cucumis sativus L.; Pesticide residue; Genetic analysis; Simple sequence repeats; Quantitative trait locus

\section{INTRODUCTION}

Large amounts of pesticides are used worldwide to achieve high crop yields, especially for the cultivation of greenhouse vegetables, which in turn results in high levels of pesticide residue in food (Ngowi et al., 2007; Yang and Cao, 2012; Akoto et al., 2015). Owing to an increased awareness of food safety, reducing the levels of pesticide residues in green crops has become an important research focus. For example, recent studies have aimed to determine the mechanism of biological degradation of organic pollutants, and to develop effective measures that decrease the levels of pesticide residue (Wang et al., 2010; Megharaj et al., 2011; Abraham et al., 2013; Chishti et al., 2013). Cucumber (Cucumis sativus L.) is the most common vegetable and fruit crop grown in greenhouses (Liang et al., 2012). Its production during long-term planting is drastically reduced by downy mildew, a highly destructive leaf disease affecting the cucumber plant. In order to reduce damage to cucumber leaves during agricultural production, propamocarb has been widely applied to protect against downy mildew at the cotyledon stage, and this is the main reason that pesticide residues occur in cucumber (Ojiambo et al., 2010; Liang et al., 2012).

In order to obtain cucumber varieties that are resistant to downy mildew, cucumber species with low/high propamocarb residues were selected by Liu et al. (2010). Genes encoding resistant proteins participating in the propamocarb stress response were identified from cucumber variety D0351, which has low levels of propamocarb residue (Wu et al., $2013 \mathrm{a}, \mathrm{b})$. Overexpression of the CsABC19 gene enhanced the growth ability and resistance of Arabidopsis thaliana subjected to propamocarb stress (Meng et al., 2016). Studies of pesticide residues in vegetables have been limited to the detection of microscopic residues, and few studies have investigated the correlation between heredity of cucumber variety and pesticide residues. In this study, a genetic analysis was conducted to develop molecular markers associated with low pesticide residue in cucumber varieties. These results will provide valuable information for the study of molecular mechanisms underlying the control of pesticide residue in cucumber and provide a valuable reference for marker-assisted selection for the genetic improvement of cucumber with low pesticide residues.

\section{MATERIAL AND METHODS}

\section{Plant materials and propamocarb treatment}

Seeds of five cucumber varieties were provided by the Cucumber Breeding Group of Horticulture College of Northeast Agricultural University and cucumbers were grown in the facilities of the Horticulture Center of Northeast Agricultural University. Seeds were germinated on moist filter paper in the dark at $28^{\circ} \mathrm{C}$ for $30 \mathrm{~h}$. At the two-leaf stage, the seedlings were transplanted into a growth room with a $25^{\circ}-30^{\circ} \mathrm{C}$ (day) $/ 15^{\circ}-18^{\circ} \mathrm{C}$ (night) temperature,

Genetics and Molecular Research 15 (4): gmr15048776 
$60-75 \%$ relative humidity, and natural light conditions. The fruits set at the third node of each plant were used in subsequent investigations.

Fruits of five cucumber varieties (inbred lines), D9320, Beijin, D0313, D0328-8, and D0351, were used to measure the levels of propamocarb residue. Among them, D9320 and Beijin contained high levels of pesticide residue, and D0313, D0328-8, and D0351 showed low levels of pesticide residue. Propamocarb hydrochloride (400 ppm x 66.6\%; Karp, Shandong Sino-Agri United Biotechnology Co., Ltd. Shandong, China) was sprayed on cucumbers 34 days after transplantation, three times per week. Samples $(500 \mathrm{~g})$ were collected from each replicate and stored at $-80^{\circ} \mathrm{C}$. Ten cross combinations from five parent varieties were generated to obtain 15 combinations in 2009 (Table 1). Seeds of $\mathrm{P}_{1}, \mathrm{P}_{2}, \mathrm{~F}_{1}$, and $\mathrm{F}_{2}$ generations were obtained from the parental lines D9320 x D0351, and the $F_{1}$ and $F_{2}$ generations. A random complete block design was used with three replicates. Field management corresponded to that used for usual cucumber cultivation, where parents and each combination were bred under the same conditions and their growth was carefully recorded for 7 days.

Table 1. Combining ability variance of pesticide residues in cucumber.

\begin{tabular}{l|c|c|c|c|c}
\hline Source of variance & Degrees of freedom & Sum of squares & Mean squares & $F$ value & P value \\
\hline GCA & 4 & 3618.314 & 904.579 & $335.029^{* *}$ & 0.0001 \\
\hline SCA & 9 & 1169.652 & 129.961 & $48.133^{* *}$ & 0.0001 \\
\hline Error & 36 & 97.185 & 2.70 & & \\
\hline
\end{tabular}

**Significant differences by the LDS-test $(\mathrm{P} \leq 0.0001)$.

\section{Hybridized combinations and quantitative trait locus (QTL) mapping}

Different hybridized combinations were prepared based on a complete diallel cross design II 1/2p (p+1) (Griffing, 1955). Because D9320-2 x D0351 exhibited the largest difference in pesticide residue among cucumber combinations, these two varieties were used as parents to establish an $\mathrm{F}_{2}$ population, including 356 strains. A genetic analysis of pesticide residue was performed on parent plants (D9320-2 and D0351), and on the $F_{1}$ and $F_{2}$ generations of cucumbers using QGA Station 1.0 software. According to the analysis results, 356 individuals of $\mathrm{F}_{2}$ population were screened as the optimal combination to identified and construct genetic map. Levels of propamocarb residue in the parents and $\mathrm{F}_{2}$ progenies were measured by gas chromatography (GC) as previously described (Manikrao and Mohapatra, 2015). Genetic linkage maps were developed using the JoinMap 4.0 mapping software. Simple sequence repeat (SSR) markers were identified and used to construct a genetic linkage map. QTLs in plants containing pesticide residues were identified using the composite interval mapping method of Windows using QTL Cartographer V2.0 software.

\section{Quantitative real-time polymerase chain reaction (qRT-PCR) analysis}

Total DNA was extracted from the leaves of cucumber plants using the modified cetyltrimethyl-ammonium bromide method (Wang et al., 2006). A total of 112 pairs of amplification primers were selected, of which 45 pairs amplified well. Using the bulked segregation analysis method, a DNA mixing pool model was developed (Michelmore et al., 1991) and six pairs of differential primers were selected from 26 pairs of SSR primers. The primers were used for amplification in $\mathrm{F}_{2}$ populations (200 strains) to construct genetic linkage maps of cucumber.

Genetics and Molecular Research 15 (4): gmr15048776 
Three independent biological replicates of each sample and three technical replicates of each biological replicate were analyzed in the Bio-Rad DNA Engine PCR System (ALD1244, Mexico). The SSR reaction system $(20 \mu \mathrm{L})$ consisted of $\mathrm{ddH}_{2} \mathrm{O}(11.3 \mu \mathrm{L}), 10 \mathrm{X}$ buffer $(2 \mu \mathrm{L})$, $2.5 \mathrm{mM} \mathrm{Mg}{ }^{2+}(2.0 \mu \mathrm{L}), 2.5 \mathrm{mM}$ dNTPs $(2.0 \mu \mathrm{L}), 20 \mathrm{ng} / \mu \mathrm{L}$ template DNA $(2 \mu \mathrm{L})$, Taq DNA $(0.2 \mu \mathrm{L})$, and $10 \mathrm{pmol} / \mu \mathrm{L}$ upstream and downstream primers $(0.25 \mu \mathrm{L})$. PCR amplification was performed under the following conditions: $5 \mathrm{~min}$ at $94^{\circ} \mathrm{C}$, followed by 35 cycles of $30 \mathrm{~s}$ at $94^{\circ} \mathrm{C}, 1 \mathrm{~min}$ at $49^{\circ} \mathrm{C}$ (dependent on primers), and $10 \mathrm{~min}$ at $72^{\circ} \mathrm{C}$, with a final extension of $10 \mathrm{~min}$ at $72^{\circ} \mathrm{C}$, after which the reaction mixture was held at $12^{\circ} \mathrm{C}$.

Five cucumber varieties, D9320-2, Beijin, D0313, D0328-6, and D0351, were designated as 1, 2, 3, 4 and 5, respectively. Statistical analyses, genetic correlation analysis, and combination ability analysis of data were performed using SAS 9.2. Moreover, additivedominance genetic models were analyzed using the QGA Station 1.0 software. To determine the linkage groups and chromosomes corresponding to pesticide genes, a comparative analysis was performed using the MapInspect software (http://mapinspect.software.informer.com).

\section{Detection of pesticide residues}

Samples of cucumber $(25 \mathrm{~g})$ were added to $80 \mathrm{~mL}$ acetone/water $(7: 1 \mathrm{v} / \mathrm{v})$, and then homogenized at high speed for $5 \mathrm{~min}$. The residue was washed twice with acetone/water. The filtrate was mixed and concentrated to $40 \mathrm{~mL}$ at a temperature lower than $45^{\circ} \mathrm{C}$. The extract was transferred to a $250-\mathrm{mL}$ separation funnel containing $50 \mathrm{~mL}$ ether and $5 \mathrm{~g}$ sodium chloride. The mixture was shaken and separated into an aqueous phase and an upper organic phase. The separation process was repeated twice. The ether layers were combined and added to the organic phase before dehydration in the chromatographic column. The extract was concentrated to near dryness with a rotary evaporator at $65^{\circ} \mathrm{C}$ and then dissolved in $1 \mathrm{~mL}$ methanol, which was used for detection by GC.

A stock solution of propamocarb $(0.1 \mathrm{mg} / \mathrm{mL})$ was prepared by dissolving $10 \mathrm{mg}$ propamocarb in $100 \mathrm{~mL}$ methanol. This was then diluted 1:10 to produce an intermediate solution of $10 \mu \mathrm{g} / \mathrm{mL}$, which was used to generate six propamocarb standard solutions (5.0, $1.0,0.5,0.1,0.02$, and $0.01 \mu \mathrm{g} / \mathrm{mL}$ ). Gas chromatograms of the six propamocarb standard solutions were generated under the chromatographic conditions described by the methods of Manikrao and Mohapatra (2015). Propamocarb standard curves and correlation coefficients were obtained by plotting the peak areas against the sample concentrations. Chromatographic column: ShimadzuRtx-1 capillary column ( $30 \mathrm{~m}$ x $0.25 \mathrm{~mm}$ x $0.25 \mu \mathrm{m})$; detector: FID; carrier gas $\left(\mathrm{N}_{2}\right): 30 \mathrm{~mL} / \mathrm{min}$; air: $400 \mathrm{~mL} / \mathrm{min}$; hydrogen: $40 \mathrm{~mL} / \mathrm{min}$; temperature programming: $70^{\circ} \mathrm{C}$ for $3 \mathrm{~min}$, raised to $230^{\circ} \mathrm{C}$ at a velocity of $30^{\circ} \mathrm{C} / \mathrm{min}, 230^{\circ} \mathrm{C}$ for $10 \mathrm{~min}$; inlet temperature: $260^{\circ} \mathrm{C}$; detector temperature: $290^{\circ} \mathrm{C}$. According to the retention time of the pesticide standards, the concentrations of propamocarb residue were quantified using the external standard method.

\section{RESULTS}

\section{Pesticide residue analysis and combination ability analysis in cucumber fruits}

To detect pesticide residues in cucumber fruits, propamocarb standards were analyzed by GC. A peak at $10.8 \mathrm{~min}$ was observed in the $0.5 \mu \mathrm{g} / \mathrm{mL}$ propamocarb sample, indicating that the test results were accurate (Figure 1A). The standard curve revealed a good linear

Genetics and Molecular Research 15 (4): gmr15048776 
relationship. The linear equation obtained was $\mathrm{Y}=1534.7+15333.9 \mathrm{X}$ with a correlation coefficient of 0.994 and a concentration range of $0.01-5 \mu \mathrm{g} / \mathrm{mL}$. The results suggest that the $\mathrm{GC}$ method could be used to qualitatively and quantitatively analyze propamocarb concentration. In addition, levels of pesticide residues in different cucumber varieties showed significant differences based on GC analysis. Fresh D9320-2 and Beijin fruits contained higher levels of residues than the other cucumber varieties, while D0351 and pickled cucumbers showed lower levels of pesticide residue than did the others (Figure 1B).
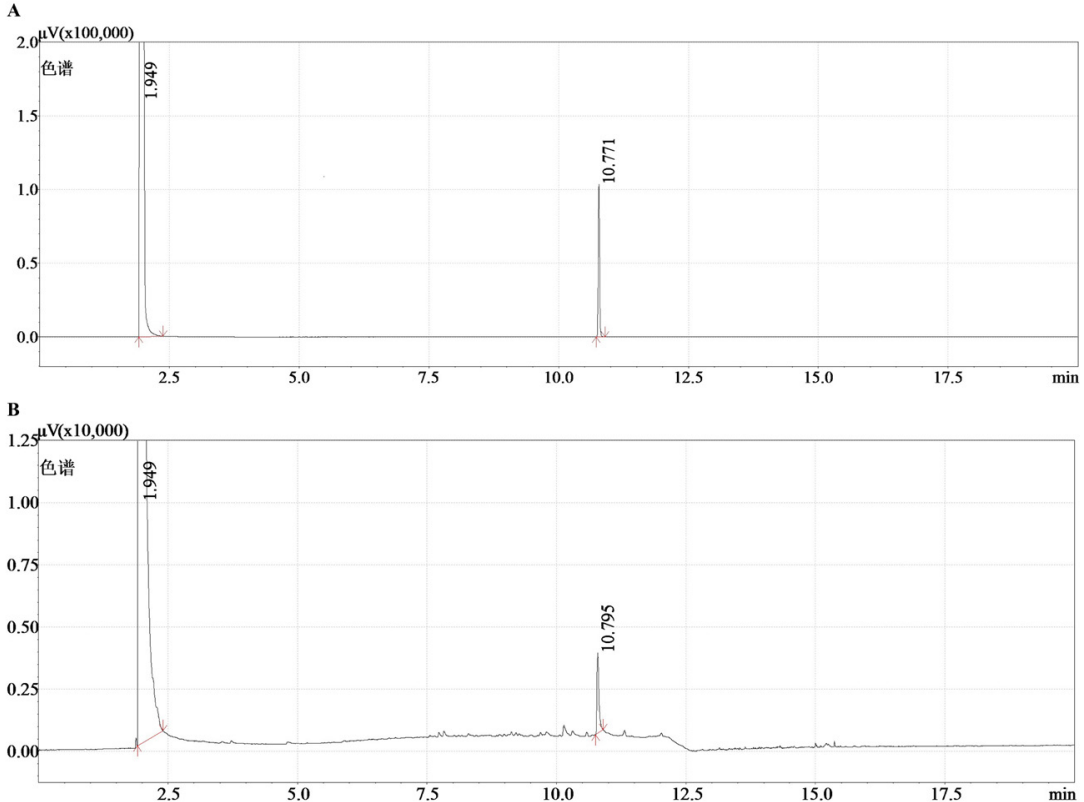

Figure 1. Gas chromatogram of the $0.5 \mu \mathrm{g} / \mathrm{mL}$ propamocarb standard. Gas chromatogram of the D9320 sample.

To determine the genetic attributes of pesticide residues, a combination ability analysis was performed. We found that the general combination ability (GCA) of parents differed significantly. Furthermore, the specific combination ability (SCA) of different combinations differed significantly (Table 1). The combinations D9320-2 x D0313 and D0313 x D0351 had statistical significance compared with the other eight combinations (Table 2). The combination ability of each inbred line was evaluated (Table 3 ). Interestingly, D9320-2 and Beijin had the maximum GCA but the minimum SCA among inbred lines, thus revealing that their individual characteristics were stable. The inbred line D0328-6 showed a low GCA level and low variation, which indicated that this inbred line was unlikely to produce good F1 combinations. The cross combination D9320-2 x D0313 exhibited the highest GCA and SCA of all inbred lines. Based on these results, D9320-2 $x$ D0313 was selected to establish the $\mathrm{F}_{2}$ population. Normality testing revealed that the $\mathrm{F}_{2}$ population was normally distributed (kurtosis $=0.1317<1$, deviation $=0.09814<1$, Shapiro-Wilk $=0.3748>0.05)($ Figure 2$)$. However, pesticide residues showed continuous variations rather than proportional relationships. Therefore, pesticide residue might be considered as a quantitative trait that is controlled by multiple genes.

Genetics and Molecular Research 15 (4): gmr15048776 
Table 2. Analysis of special combining ability (SCA) effect.

\begin{tabular}{l|c|c}
\hline Cross & Effect of SCA & Difference effect of SCA \\
\hline $1 \times 2$ (CK) & -6.11 & $24.66^{*}$ \\
\hline $1 \times 3$ & 18.55 & 2.74 \\
\hline $1 \times 4$ & -3.37 & 17.56 \\
\hline $1 \times 5$ & 11.45 & 7.23 \\
\hline $2 \times 3$ & 1.12 & 1.34 \\
\hline $2 \times 4$ & -4.77 & 17.82 \\
\hline $2 \times 5$ & 11.71 & -0.12 \\
\hline $3 \times 4$ & -6.23 & $23.37^{*}$ \\
\hline $3 \times 5$ & 17.26 & -15.02 \\
\hline $4 \times 5$ & -21.13 & \multicolumn{2}{|c}{} \\
\hline
\end{tabular}

*Significant differences by the LSD-test $(\mathrm{P} \leq 0.005)$.

Table 3. Synthesis assessment of combining ability on an inbred cucumber line.

\begin{tabular}{l|c|c}
\hline Inbred line & Effect of GCA & Mean square of SCA \\
\hline 1 & 9.24 & 139.70 \\
\hline 2 & 13.28 & 180.21 \\
\hline 3 & -4.94 & 431.63 \\
\hline 4 & -5.06 & 113.91 \\
\hline 5 & 11.01 & 203.37 \\
\hline
\end{tabular}

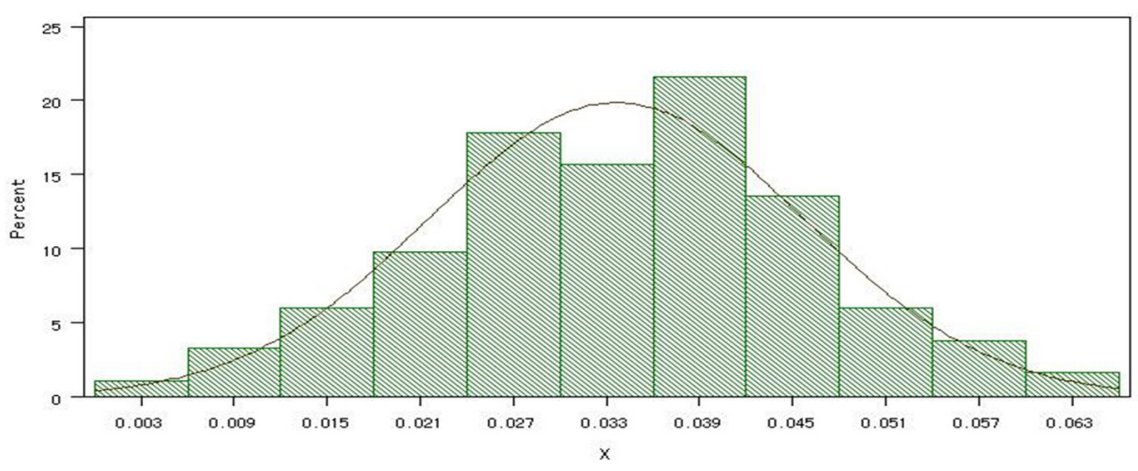

Figure 2. Simulated high-resolution normal distribution of the F2 population.

\section{Establishing a genetic model and genetic linkage map in $C$. sativus $\mathrm{L}$.}

An additive-dominant genetic model showed that although the dominant effect of pesticide residues was relatively low in cucumber, the additive effect was highly significant (Table 4), which shows there is high heritability of pesticide residues in cucumber. The interaction between the additive effect and the environment was not significant; however, no interaction was observed between the dominant effect and the environment. In addition, the standard error was estimated to be 21.738 , indicating that the existence of environmental factors influenced the levels of pesticide residues in cucumber. Overall, the heredity of pesticide residues was dominated by an additive effect in cucumber, which is not significantly influenced by the environment. The heritability of pesticide residue in cucumber was calculated using the formula described by Achouch (2002). The broad-sense heritability exceeded 50\%,

Genetics and Molecular Research 15 (4): gmr15048776 
which was greater than the narrow-sense heritability (Table 5). The marked difference between the broad- and narrow-sense heritability suggested that the levels of pesticide residues were significantly influenced by non-additive factors in cucumber. To identify agronomic traits possibly associated with pesticide residues, some important morphological indexes related to pesticide residue heredity in cucumber were measured, such as the length and circumference of cucumber, leaf area, and thorn density. A significant positive correlation was identified between leaf area and levels of pesticide residue $(r=0.9217 ; \mathrm{P}<0.0001)$, but no correlation was observed in cucumber.

\begin{tabular}{l} 
Table 4. Genetic variance of pesticide residues in cucumber. \\
\begin{tabular}{l|c|c}
\hline Variance component & Estimated value (\%) & Standard error \\
\hline $\mathrm{V}_{\mathrm{A}} / \mathrm{V}_{\mathrm{P}}$ & $46.459^{* *}$ & 2.316 \\
\hline $\mathrm{V}_{\mathrm{D}} / \mathrm{V}_{\mathrm{P}}$ & $30.27^{* *}$ & 2.011 \\
\hline $\mathrm{V}_{\mathrm{AE}} / \mathrm{VP}_{\mathrm{P}}$ & $9.451^{* *}$ & 1.574 \\
\hline $\mathrm{V}_{\mathrm{E}} / \mathrm{V}_{\mathrm{P}}$ & $21.738^{* *}$ & 2.691 \\
\hline
\end{tabular} \\
\hline
\end{tabular}

** Significant differences by the LSD-test $(\mathrm{P} \leq 0.0001)$.

Table 5. Heritability of pesticide residue levels in cucumber.

\begin{tabular}{l|c|c}
\hline Rate of variance component & Estimated value & Standard error \\
\hline $\mathrm{h}_{2}(\mathrm{~N})$ & $36.210 \%$ & 0.024 \\
\hline $\mathrm{h}_{2}(\mathrm{~B})$ & $51.336 \%$ & 0.036 \\
\hline $\mathrm{h}_{2}(\mathrm{NE})$ & $9.250 \%$ & 0.020 \\
\hline $\mathrm{h}_{2}(\mathrm{BE})$ & $14.291 \%$ & 0.037 \\
\hline
\end{tabular}

Two varieties, D9320 and D0351, were used to screen 116 pairs of SSR primers, 112 of which generated amplification products. Of these, 45 pairs of primers amplified well in the two parents. For each trait, eight plants were further screened using gene pools. Six polymorphic markers, CSWTA04, CSWCT05B, CSWCT25, CSWTA06, CSWCT14, and CSWTG03, were identified (Figure 3). The linkage groups were identified based on the molecular marker linkage maps, which contained four SSR loci (CSWCT14, CSWCT25, CSWTG03, and CSWCT05B) and the genetic distances of two markers were $22.5,7.9$, and $12.5 \mathrm{cM}$, respectively. The total length of the linkage group was $42.9 \mathrm{cM}$, and the average distance between markers was 14.3 cM. QTL analyses were conducted to analyze the levels of pesticide residue in cucumber. QCp1, detected in our study as a pesticide residue-related QTL, is located between CSWCT14 and CSWCT05B (genetic distance of $6.3 \mathrm{cM}$ from CSWCT25; LOD score of 3.4, and interpretable phenotypic variation rate of $13.63 \%$; Figure 4 and Table 6).

Table 6. Quantitative trait locus (QTL) analysis of pesticide residues in cucumber.

\begin{tabular}{l|c}
\hline Traits & Pesticide residues \\
\hline QTL & $Q C p 1$ \\
\hline Position (cM) & 26.7 \\
\hline Marker interval & CSWCT25-CSWTG03 \\
\hline LOD value & 3.4 \\
\hline$r^{2}(\%)$ & 13.63 \\
\hline Additive effect & 26.64 \\
\hline
\end{tabular}

Genetics and Molecular Research 15 (4): gmr15048776 


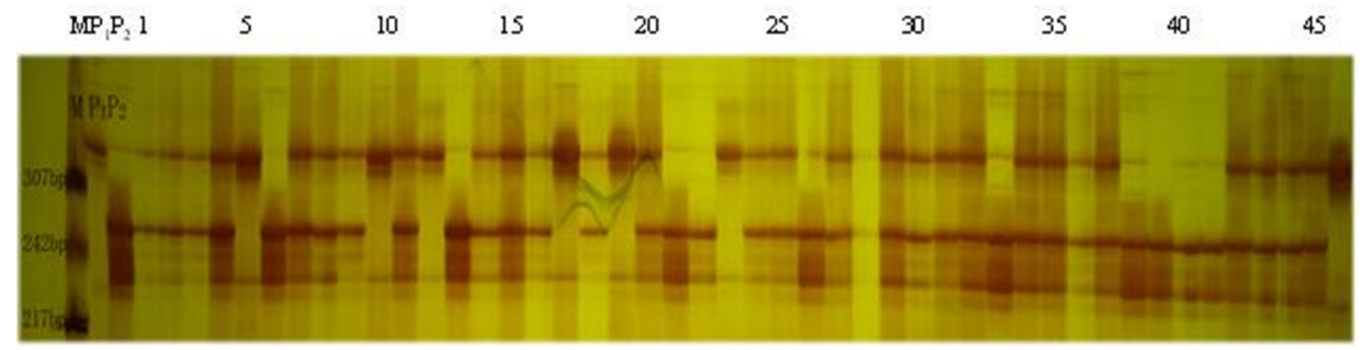

Figure 3. CSWTG03 primer amplification. P1: D0351; P2: D9320; lanes 1-45= some plants in the F2 population.

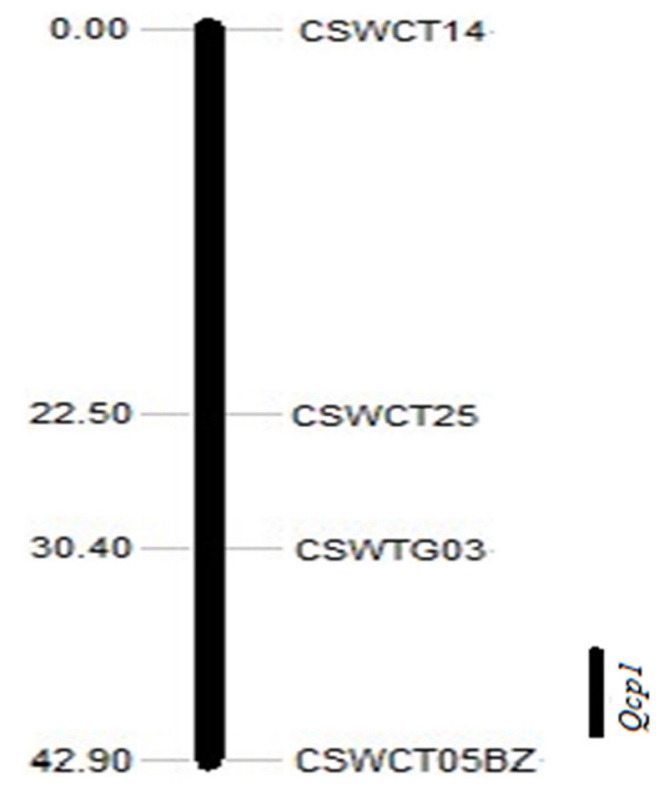

Figure 4. Distribution of pesticide-residue tolerance in a molecular linkage group.

\section{Comparative analyses of QTLs related to pesticide residue}

To map QTLs on the corresponding chromosomes, the genetic map of cucumber was compared with the LG6 map. The four SSR markers from the linkage group were located on the gene related to pesticide residue (Figure 5). QCpl was located on the sixth chromosome in the LG6 map. Therefore, we concluded that this linkage group corresponded to the sixth chromosome in cucumber. In addition, $Q C p 1$ was an effectincreasing locus (Table 6), which revealed that the QTL effect-increasing gene was derived from D9320 with high pesticide residue. Therefore, we can infer that this QTL is closely related to the level of pesticide residue in cucumber.

Genetics and Molecular Research 15 (4): gmr15048776 


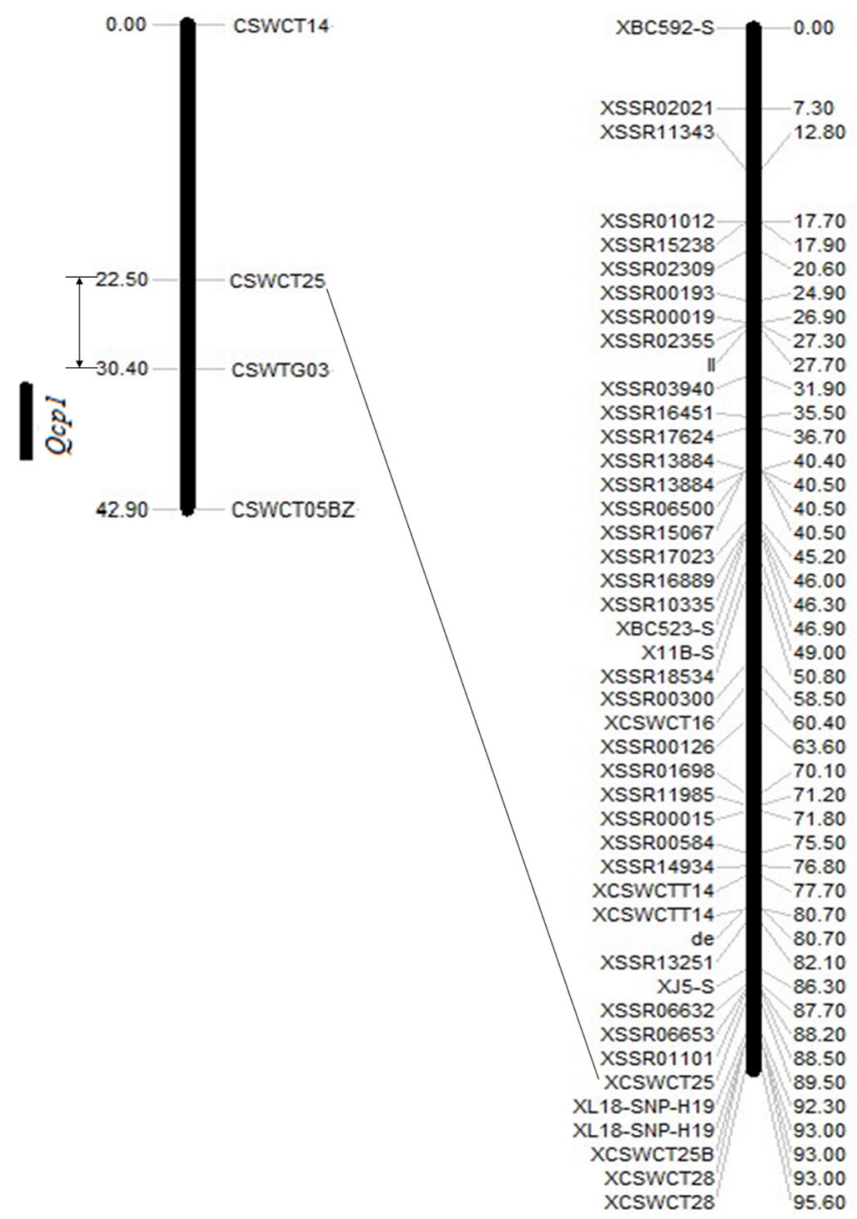

Figure 5. Marker-order comparison on chromosome 6 of cucumber constructed from the Gy 7 x H-19 map and this study map. Right: study map. Left: LG6 of Gy7 x H-19 map.

\section{DISCUSSION}

Studies on pesticide residues in plants have mainly focused on pesticide metabolism and resistance. For example, several studies have concentrated on the regulatory effects of cytochrome $\mathrm{P} 450$, glutathione, and the $\mathrm{ABC}$ transporter protein on pesticide metabolism in plants (Shiota et al., 1996; Brazier-Hicks et al., 2008; Meng et al., 2016). The GC technique has been widely used to analyze pesticide residues of relatively small molecular weight, high volatility, and heat-stability (González-Rodríguez et al., 2008; Swarnam and Velmurugan, 2013). In our study, GC was used to analyze the levels of propamocarb residue in cucumber fruits. There is limited information on the molecular mechanisms controlling pesticide residue in terms of the genetics and breeding of cucumber.

The first high-density cucumber genetic linkage map was constructed using data from the cucumber genome (Ren et al., 2009), and many molecular markers (such as $l l, d e, D$, ss,

Genetics and Molecular Research 15 (4): gmr15048776 
$u, v-1, b i, C c u$, and $T u$ ) were found to be closely linked to genes governing important agronomic traits in cucumber (Yuan et al., 2008; Huang et al., 2009; Weng, 2010; Zhang et al., 2010a,b; Li et al., 2011). Complete genome genetic linkage maps containing more than 3.6 million loci have been developed by deep re-sequencing of 115 cucumber varieties (Qi et al., 2013). In addition, 12 QTLs have been identified by analyzing the length and diameter of cucumber fruits at different developmental stages using different QTL models (Weng et al., 2015). In the present study, 116 pairs of cucumber SSR primers were used to construct linkage groups that had a low density and a large distance between markers. It is possible that the fewer number of primers used to establish genetic linkage groups. Therefore, high primer density was required for SSR markers linked to target traits in the future researches. Moreover, a QTL, CSWCT14 (16.2)-QCp1-CSWCT05B, was found at a distance of $6.3 \mathrm{cM}$ from the nearest marker with a contribution rate of $13.63 \%$ and an additive effect of 26.64, which was related to pesticide residues in cucumber.

QTLs with positive additive effects revealed that alleles carried by field-collected parents could improve the value of characteristics (Miao et al., 2012). In the present study, the detected QTL associated with pesticide residue was an effect-increasing locus with a positive additive effect. The results indicated that genes carried by the D9320 parent, which had a high residue content, plays a role in increasing the level of pesticide residue. The detection of QTLs is limited by population size, threshold, marker number, and heritability of target traits (Takagi et al., 2013). Taking recombinant inbred populations, and $\mathrm{F}_{2}$ and $\mathrm{F}_{2: 3}$ segregation populations for mapping, QTLs with a contribution of $15 \%$ can be considered as major (LOD > 2.0); but others with a contribution of 5\%, was considered as a micro-effect QTL (Miao, et al., 2011; Zhang, et al., 2011). The $\mathrm{F}_{2}$ population was used in this study and a QTL related to pesticide residue (LOD $>2.5$ ) with a contribution of $13.63 \%$ was detected, indicating that the locus can control the level of pesticide residue in cucumber. However, because $Q C p 1$ is located far from two adjacent markers it is unsuitable for cloning. Therefore, in future studies it will be necessary to screen SSR primers when applied to identify QTLs associated with pesticide residue in cucumber fruits.

\section{Conflicts of interest}

The authors declare no conflict of interest.

\section{ACKNOWLEDGMENTS}

Research funded by the National Natural Science Foundation of China (\#31272158 and \#31401863), the Doctoral Starting-up Foundation of Northeast Agricultural University (\#2012RCB25), the Open Project of Heilongjiang Provincial Key University Laboratory of Cold Area Vegetable Biology (\#CVB2012-001), the Young Talents' Project of Northeast Agricultural University (\#14QC12), the Natural Science Foundation of Heilongjiang Province (\#QC2012C122), and the Certificate of China Postdoctoral Science Foundation (\#2013M540265) and Certificate of Heilongjiang Postdoctoral Fund (\#LBH-Z12037).

\section{REFERENCES}

\footnotetext{
Abraham J, Shanker A and Silambarasan S (2013). Role of Gordonia sp JAAS1 in biodegradation of chlorpyrifos and its hydrolysing metabolite 3,5,6-trichloro-2-pyridinol. Lett. Appl. Microbiol. 57: 510-516. http://dx.doi.org/10.1111/ $\underline{\text { lam. } 12141}$
}

Genetics and Molecular Research 15 (4): gmr15048776 
Achouch A (2002). Simulation studies for comparing genetics models with additive-dominance-maternal effects and GE interaction effects. J. Biomathemat. 17: 208-214.

Akoto O, Gavor S, Appah MK and Apau J (2015). Estimation of human health risk associated with the consumption of pesticide-contaminated vegetables from Kumasi, Ghana. Environ. Monit. Assess. 187: 244. http://dx.doi.org/10.1007/ $\underline{\text { s10661-015-4471-0 }}$

Brazier-Hicks M, Evans KM, Cunningham OD, Hodgson DRW, et al. (2008). Catabolism of glutathione conjugates in Arabidopsis thaliana. Role in metabolic reactivation of the herbicide safener fenclorim. J. Biol. Chem. 283: 2110221112. http://dx.doi.org/10.1074/jbc.M801998200

Chishti Z, Hussain S, Arshad KR, Khalid A, et al. (2013). Microbial degradation of chlorpyrifos in liquid media and soil. J. Environ. Manage. 114: 372-380. http://dx.doi.org/10.1016/j.jenvman.2012.10.032

González-Rodríguez RM, Rial-Otero R, Cancho-Grande B and Simal-Gándara J (2008). Determination of 23 pesticide residues in leafy vegetables using gas chromatography-ion trap mass spectrometry and analyte protectants. $J$. Chromatogr. A 1196-1197: 100-109. http://dx.doi.org/10.1016/j.chroma.2008.02.087

Griffing B (1955). Concept of general and specific combining ability in relation to diallel cross. Aust. J. Biol. Sci. 9: 463493. http://dx.doi.org/10.1071/BI9560463

Huang S, Li R, Zhang Z, Li L, et al. (2009). The genome of the cucumber, Cucumis sativus L. Nat. Genet. 41: 1275-1281. http://dx.doi.org/10.1038/ng.475

Li Y, Yang L, Pathak M, Li D, et al. (2011). Fine genetic mapping of cp: a recessive gene for compact (dwarf) plant architecture in cucumber, Cucumis sativus L. Theor. Appl. Genet. 123: 973-983. http://dx.doi.org/10.1007/s00122$\underline{011-1640-6}$

Liang Y, Wang W, Shen Y, Liu Y, et al. (2012). Effects of home preparation on organophosphorus pesticide residues in raw cucumber. Food Chem. 133: 636-640. http://dx.doi.org/10.1016/j.foodchem.2012.01.016

Liu FF, Qin ZW and Zhou XY (2010). Screening germplasm resources of cucumber plant with low pesticide residue content. J. Northeast Agric. Univ. 41: 32-36.

Manikrao G and Mohapatra S (2015). Persistence and dissipation of fluopicolide and propamocarb on cabbage and soil under semi-arid climatic conditions. Int. J. Environ. Anal. Chem. 96: 1-19.

Megharaj M, Ramakrishnan B, Venkateswarlu K, Sethunathan N, et al. (2011). Bioremediation approaches for organic pollutants: a critical perspective. Environ. Int. 37: 1362-1375. http://dx.doi.org/10.1016/j.envint.2011.06.003

Meng JJ, Qin ZW, Zhou XY and Xin M (2016). An ATP-binding cassette transporter gene from Cucumis sativus L., CsABC19, is involved in propamocarb stress in Arabidopsis thaliana. Plant Mol. Biol. Rep. 34: 947.

Miao H, Zhang SP, Wang XW, Zhang ZH, et al. (2011). A linkage map of cultivated cucumber (Cucumis sativus L.) with 248 microsatellite marker loci and seven genes for horticulturally important traits. Euphytica 182: 167-176. http:// dx.doi.org/10.1007/s10681-011-0410-5

Miao H, Gu XF, Zhang SP, Zhang ZH, et al. (2012). Detection of quantitative trait loci for plant height in different environments using an RIL population in cucumber. Zhongguo Nong Ye Ke Xue 45: 4552-4560.

Michelmore RW, Paran I and Kesseli RV (1991). Identification of markers linked to disease-resistance genes by bulked segregant analysis: a rapid method to detect markers in specific genomic regions by using segregating populations. Proc. Natl. Acad. Sci. USA 88: 9828-9832. http://dx.doi.org/10.1073/pnas.88.21.9828

Ngowi AV, Mbise TJ, Ijani AS, London L, et al. (2007). Pesticides use by smallholder farmers in vegetable production in Northern Tanzania. Crop Prot. 26: 1617-1624. http://dx.doi.org/10.1016/j.cropro.2007.01.008

Ojiambo PS, Paul PA and Holmes GJ (2010). A quantitative review of fungicide efficacy for managing downy mildew in cucurbits. Phytopathology 100: 1066-1076. http://dx.doi.org/10.1094/PHYTO-12-09-0348

Qi J, Liu X, Shen D, Miao H, et al. (2013). A genomic variation map provides insights into the genetic basis of cucumber domestication and diversity. Nat. Genet. 45: 1510-1515.http://dx.doi.org/10.1038/ng.2801

Ren Y, Zhang Z, Liu J, Staub JE, et al. (2009). An integrated genetic and cytogenetic map of the cucumber genome. PLoS One 4: e5795. http://dx.doi.org/10.1371/journal.pone.0005795

Shiota N, Inui H and Ohkawa H (1996). Metabolism of the herbicide chlortoluron in transgenic tobacco plants expressing the fused enzyme between rat cytochrome P4501A1 and yeast NADPH-cytochrome P450 oxidoreductase. Pestic. Biochem. Physiol. 54: 190-198. http://dx.doi.org/10.1006/pest.1996.0023

Swarnam TP and Velmurugan A (2013). Pesticide residues in vegetable samples from the Andaman Islands, India. Environ. Monit. Assess. 185: 6119-6127.http://dx.doi.org/10.1007/s10661-012-3012-3

Takagi H, Abe A, Yoshida K, Kosugi S, et al. (2013). QTL-seq: rapid mapping of quantitative trait loci in rice by whole genome resequencing of DNA from two bulked populations. Plant J. 74: 174-183. http://dx.doi.org/10.1111/ tpj. 12105

Wang HJ, Wu Y, Gu W, Sun XD, et al. (2006). Extraction of DNA from cucumber by improved CTAB method. Heilongjiang Agric. Sci 5: 124-125.

Genetics and Molecular Research 15 (4): gmr15048776 
Wang J, Jiang Y, Chen S, Xia X, et al. (2010). The different responses of glutathione-dependent detoxification pathway to fungicide chlorothalonil and carbendazim in tomato leaves. Chemosphere 79: 958-965. http://dx.doi.org/10.1016/j. chemosphere.2010.02.020

Weng Y, Colle M, Wang Y, Yang L, et al. (2015). QTL mapping in multiple populations and development stages reveals dynamic quantitative trait loci for fruit size in cucumbers of different market classes. Theor. Appl. Genet. 128: 17471763. http://dx.doi.org/10.1007/s00122-015-2544-7

Weng YQ (2010). Genetic diversity among Cucumis metuliferus populations revealed by cucumber microsatellites. HortScience 45: 214-219.

Wu P, Qin Z, Zhao W, Zhou X, et al. (2013a). Transcriptome analysis reveals differentially expressed genes associated with propamocarb response in cucumber (Cucumis sativus L.) fruit. Acta Physiol. Plant. 35: 2393-2406. http://dx.doi. org/10.1007/s11738-013-1274-1

Wu P, Qin Z, Wu T, Zhou X, et al. (2013b). Proteomic analysis of cucumber defense responses induced by propamocarb. J. Integr. Agric. 12: 2022-2035. http://dx.doi.org/10.1016/S2095-3119(13)60370-6

Yang J and Cao HF (2012). Determination of 14 organophosphorus in cucumber of green vegetables fruits by using gas chromatography North Hortic. 12: 25-28.

Yuan XJ, Pan JS, Cai R, Liu LZ, et al. (2008). Genetic mapping and QTL analysis of fruit and flower related traits in cucumber (Cucumis sativus L.) using recombinant inbred lines. Euphytica 164: 473-491. http://dx.doi.org/10.1007/ $\underline{\text { s10681-008-9722-5 }}$

Zhang SP, Miao H, Gu XF, Yang YH, et al. (2010a). Genetic mapping of the scab resistance gene Ccu in cucumber. $J$. Am. Soc. Hortic. Sci. 135: 53-58.

Zhang SP, Liu MM, Mian H, Zhang SQ, et al. (2011). QTL mapping of resistance genes to powdery mildew in cucumber (Cucumis sativus L.). Zhongguo Nong Ye Ke Xue 44: 3584-3593.

Zhang W, He H, Guan Y, Du H, et al. (2010b). Identification and mapping of molecular markers linked to the tuberculate fruit gene in the cucumber (Cucumis sativus L.). Theor. Appl. Genet. 120: 645-654. http://dx.doi.org/10.1007/ $\underline{\mathrm{s} 00122-009-1182-3}$

Genetics and Molecular Research 15 (4): gmr15048776 